\title{
Flame aerosol deposition of Y2O3:Eu nanophosphor screens and their photoluminescent performance
}

\author{
Journal Article \\ Author(s): \\ Kubrin, Roman; Tricoli, Antonio; Camenzind, Adrian; Pratsinis, Sotiris E.; Bauhofer, Wolfgang \\ Publication date: \\ 2010-05-07 \\ Permanent link: \\ https://doi.org/10.3929/ethz-b-000162125
}

Rights / license:

Creative Commons Attribution 3.0 Unported

Originally published in:

New Journal of Physics 21(22), https://doi.org/10.1088/0957-4484/21/22/225603 


\section{Related content}

\section{Flame aerosol deposition of $\mathrm{Y}_{2} \mathrm{O}_{3}$ : Eu nanophosphor screens and their photoluminescent performance}

To cite this article: Roman Kubrin et al 2010 Nanotechnology 21225603

View the article online for updates and enhancements.
Photoluminescence of $\left(\mathrm{YGd}_{2} \mathrm{O}_{3}: \mathrm{Eu}\right.$ phosphors produced by nanoparticleseeded flame-assisted spray pyrolysis R Kubrin, J Huang, F Moglia et al.

Combustion synthesis of novel Li0.9Y(0.9x-y)Zr0.1O2:Eux3 +, Ry3+ (R = Ce, Bi) redluminescence nanocrystal and $\frac{\text { emission-mechanism research }}{\text { Zifeng Qiu, Yuanyuan Zhou, Mengkai Lü }}$ et al.

- Selective phase synthesis of a high luminescence Gd2O3:Eu nanocrystal phosphor throughdirect solution combustion

Guodong Xia, Sumei Wang, Shengming Zhou et al.

\section{Recent citations}

- Morphology control and
$\frac{\text { photoluminescence properties of Eu3+- }}{\text { activated Y4Al2O9 nanophosphors for }}$
$\frac{\text { solid state lighting applications }}{\text { Antika Das et al }}$
- Flame aerosol synthesis of nanostructured
$\frac{\text { materials and functional devices: }}{\text { Processing, modeling, and diagnostics }}$
Shuiqing Li et al
- Transparent nanophosphor films with high
$\frac{\text { quantum efficiency through cold }}{\text { compaction }}$
R. Kubrin et al

\section{IOP ebooks}

Bringing you innovative digital publishing with leading voices to create your essential collection of books in STEM research. Start exploring the collection - download the first chapter of every title for free. 


\title{
Flame aerosol deposition of $\mathrm{Y}_{2} \mathrm{O}_{3}: \mathrm{Eu}$ nanophosphor screens and their photoluminescent performance
}

\author{
Roman Kubrin $^{1,3}$, Antonio Tricoli ${ }^{2}$, Adrian Camenzind ${ }^{2,4}$, \\ Sotiris E Pratsinis ${ }^{2}$ and Wolfgang Bauhofer ${ }^{1}$ \\ ${ }^{1}$ Institute for Optical and Electronic Materials, Hamburg University of Technology (TUHH), \\ Eissendorfer Strasse 38, D-21073 Hamburg, Germany \\ 2 Department of Mechanical and Process Engineering, Particle Technology Laboratory, \\ Institute of Process Engineering, Sonneggstrasse 3, ETH Zurich, CH-8092 Zurich, Switzerland \\ E-mail: roman.kubrin@tu-harburg.de
}

Received 10 March 2010, in final form 14 April 2010

Published 7 May 2010

Online at stacks.iop.org/Nano/21/225603

\begin{abstract}
Screens of $\mathrm{Y}_{2} \mathrm{O}_{3}: \mathrm{Eu}^{3+}$-nanophosphor $\left(d_{\mathrm{BET}}=24 \mathrm{~nm}\right)$ with coating densities in the range $0.23-3.8 \mathrm{mg} \mathrm{cm}^{-2}$ were obtained by flame aerosol deposition (FAD) from nitrate-based precursors. The average deposition rate was $0.22 \mathrm{mg} \mathrm{cm}^{-2} \mathrm{~min}^{-1}$. Porosity of the obtained deposits was $0.973 \pm 0.004$. Light scattering of the coatings in the visible range showed a Rayleigh-like dependence on wavelength and, in comparison to the screens made of the commercial micrometer-sized phosphor powder $\left(d_{\text {SEM }}=4 \mu \mathrm{m}\right)$, was reduced by up to two orders of magnitude. As a result, the nanophosphor coatings maintained nearly constant brightness in a very wide range of coating densities. Furthermore, it should be expected that a substantially improved screen resolution can be achieved with such screens. For excitation at a wavelength of $254 \mathrm{~nm}$, the maximum brightness of the FAD-deposited $\left(\mathrm{Y}_{0.92} \mathrm{Eu}_{0.08}\right)_{2} \mathrm{O}_{3}$ phosphor screens in the transmission mode was nearly one third of that of the screens made of the commercial phosphor. It was demonstrated that light reflection from the supporting substrate and porosity of the coating significantly influence its photoluminescent performance.
\end{abstract}

(Some figures in this article are in colour only in the electronic version)

\section{Introduction}

Active research on nanosized lanthanides-doped phosphors started more than a decade ago [1, 2] and, since then, significant advances have been made in the synthesis of nanophosphors and the understanding of relations between the luminescent characteristics of phosphor powders and the size and morphology of phosphor particles [3, 4]. The potential of ultrafine phosphors (i.e., those with particle size less than $100 \mathrm{~nm}$ ) has already been recognized in several fields of application, e.g., phosphor-converted light emitting diodes (LEDs) [5-7], fluorescent lamps [5], field

\footnotetext{
3 Author to whom any correspondence should be addressed. Present address: Institute for Advanced Ceramics, Hamburg University of Technology (TUHH), Denickestrasse 15, D-21073 Hamburg, Germany.

4 Present address: Optotune AG, Ueberlandstrasse 129, CH-8600 Dübendorf, Switzerland.
}

emission displays [8], biotechnology [9], and digital x-ray imaging $[10,11]$.

For the application in phosphor screens, the reduction of phosphor particle size offers the possibility of achieving higher resolution (i.e., improving the ability of the screen to reproduce small details of an image, usually expressed in the terms of modulation transfer function (MTF) [12]). For pixelated screens, the resolution is limited by pixel size and, therefore, can be improved by decreasing the pitch of the structure [13], provided that utilized phosphor particles are sufficiently small.

The resolution of unstructured (unpixelated) screens is determined, to a large extent, by the scattering of incident exciting radiation (UV-photons or electrons) and the scattering of emitted visible photons inside the phosphor layer. The latter process usually provides the main contribution to the 'smearing-out' of the image observed in the transmission mode (when the screen is placed between the excitation 
source and the detector) [14]. For particles much larger than the wavelengths of incident light, the scattering crosssection is practically wavelength-independent [15]. The same applies to the collective scattering from particle films, provided that absorption of light is negligible or very weak (otherwise, scattering and absorption coefficients depend on each other [14]).

The resolution of conventional phosphor screens can be improved by decreasing the coating density of the applied phosphor [14]. However, for standard commercial phosphor powders, the quality of image reproduction is ultimately limited by particle size [16] because the photons emitted by luminescence centers experience multiple internal reflections inside the micrometer-sized particles and can escape at any point of the particle surface $[17,18]$ (i.e., emission cannot be localized any better than the full volume of a single particle).

The optical properties of phosphor nanoparticles differ substantially from those of commercial phosphor powders. As the particle size becomes much smaller than the wavelength of light emitted by phosphors, the scattering cross-section decreases and collective scattering takes on a Rayleighlike dependence on wavelength. Furthermore, luminescent nanoparticles represent point-like emitters (the resolvable size of a single radiation source is determined by the diffraction of emitted light and not by the size of the particle). Theoretically, when luminescence is excited by strongly absorbed radiation (e.g., by UV-light), scattering of exciting radiation is also minimized, and it should be possible to create a nanophosphor screen with a resolution approaching the limits set by the diffraction of light $(0.3 \mu \mathrm{m})$, i.e., beyond 1000 line pairs $\mathrm{mm}^{-1}$, which previously could only be obtained with special pixelated screens or with nonscattering (monolithic) screens [13]. In spite of the expected advantage of nanophosphor screens for high-resolution applications (e.g., in excimer laser beam profiling or in systems for the inspection of masks for UV-photolithography), there is a lack of experimental data on their optical performance, which is explained by the complexity of synthesis of ultrafine phosphor powders and cumbersome device manufacturing.

Several methods for depositing nanophosphor screens have been proposed, e.g., electrophoretic deposition [19, 20], spin-coating [21], dip-coating [22], layer-by-layer assembly [23, 24], the Langmuir-Blodgett technique [25], and inkjet printing [26]. Generally, these are multi-step methods, i.e., synthesis and deposition of nanophosphors are carried out separately, in subsequent order. Wet batch processing limits the overall screen production rates. Therefore, robust highthroughput techniques for deposition of luminescent nanoparticles are much sought. The prompt screening of nanophosphors can be performed by combining the continuous gas-phase synthesis of nanoparticles (at possibly high rates) with the simultaneous deposition onto the final substrate. This approach is used, for example, in flame aerosol deposition (FAD) [27].

FAD is based on flame spray pyrolysis (FSP) of flammable liquid precursors and offers rather high production rates of nanoparticles [28]. FAD was applied to the synthesis of advanced gas sensors [29-31], battery electrodes [32], and anti-fogging coatings [33]. Similar techniques were used for the production of preforms for optical fibers [34], deposition of optical (non-luminescent) coatings [35], and phosphor coatings with particle size in the intermediate range between that of nanophosphors and standard commercial powders [36, 37].

Here, the first systematic study of nanoparticle phosphor screens deposited by FAD is presented. Yttrium oxide doped with europium was chosen as a phosphor material to be investigated because it is one of the best studied phosphors. It possesses unique luminescent properties and is used as a red component in high-quality fluorescent lamps and projection television [4]. Successful preparation of ultrafine $\mathrm{Y}_{2} \mathrm{O}_{3}: \mathrm{Eu}$ phosphor powders by FSP has already been reported [38, 39]. In the present study, a new composition of FSP-precursors, which allows for substantial reduction of the process costs, was used for the deposition of $\mathrm{Y}_{2} \mathrm{O}_{3}$ :Eu nanophosphor screens. The spectra of attenuance (i.e., total extinction of light due to absorption and scattering) of FAD-deposited phosphor coatings in the UV- and visible-light range and the dependence of photoluminescent (PL-)brightness on the coating density (for excitation at a wavelength of $254 \mathrm{~nm}$ ) were investigated. Finally, the influence of volumetric porosity on the optical properties of the deposited phosphor screens was assessed.

\section{Experimental details}

The $\mathrm{Y}_{2} \mathrm{O}_{3}$ :Eu nanoparticles with the cubic crystalline structure (which is preferred due to its superior luminescent properties) were prepared as follows. First, nitrates of yttrium $(99.9 \%$, ChemPur) and europium (99.9\%, Alfa Aesar) were dissolved in ethanol (EtOH, p.a.). Afterward, 2-ethylhexanoic acid (EHA, 99\%, Riedel-de Haën) was added so that a $0.5 \mathrm{M}$ solution of yttrium and europium nitrates in a solvent composed of $50 \mathrm{vol} \% \mathrm{EtOH}$ and 50 vol\% EHA was obtained. The amount of europium was varied between 0 and $12 \mathrm{~mol} \%$ of the total concentration of metal ions $(\mathrm{Y}+\mathrm{Eu})$ in the precursor solution. The process parameters for obtaining yttria nanoparticles were adopted from the work on FSP-synthesis of $\mathrm{Y}_{2} \mathrm{O}_{3}: \mathrm{Eu}$ [39]. The flammable liquid precursor was fed into a FSP-unit (see figure 1) with a syringe pump at the rate of $11.7 \mathrm{ml} \mathrm{min}{ }^{-1}$ (if not mentioned otherwise) through a capillary of an outside-mixing two-phase nozzle. The precursor was dispersed with oxygen (at the rate of $31 \mathrm{~min}^{-1}$, with a constant pressure drop of 1.5 bar over the nozzle). Next, the liquid spray was ignited with a methane/oxygen pilot flame (1.4 and $2.81 \mathrm{~min}^{-1}$, respectively).

For screen deposition, the FSP-unit was combined with a water-cooled substrate holder [40] placed $25 \mathrm{~cm}$ above the nozzle (directly above the flame tip; figure 1). Nanophosphor coatings were deposited onto fused silica slides (with a diameter of $30 \mathrm{~mm}$ and a thickness of $1 \mathrm{~mm}$ ). Powder samples were collected downstream of the substrate holder $(50 \mathrm{~cm}$ above the burner) with a vacuum pump (Vacuumbrand, RE 16) on water-cooled glass-fiber filters (GF/D Whatman, $257 \mathrm{~mm}$ diameter).

X-ray diffraction (XRD)-patterns were obtained by a Bruker, AXS D8 Advance diffractometer $(40 \mathrm{kV}, 40 \mathrm{~mA}$, $\left.\mathrm{Cu} \mathrm{K} \alpha, 2 \theta=15^{\circ}-75^{\circ}\right)$. The crystal size and weight fractions of cubic and monoclinic yttria phases were determined 


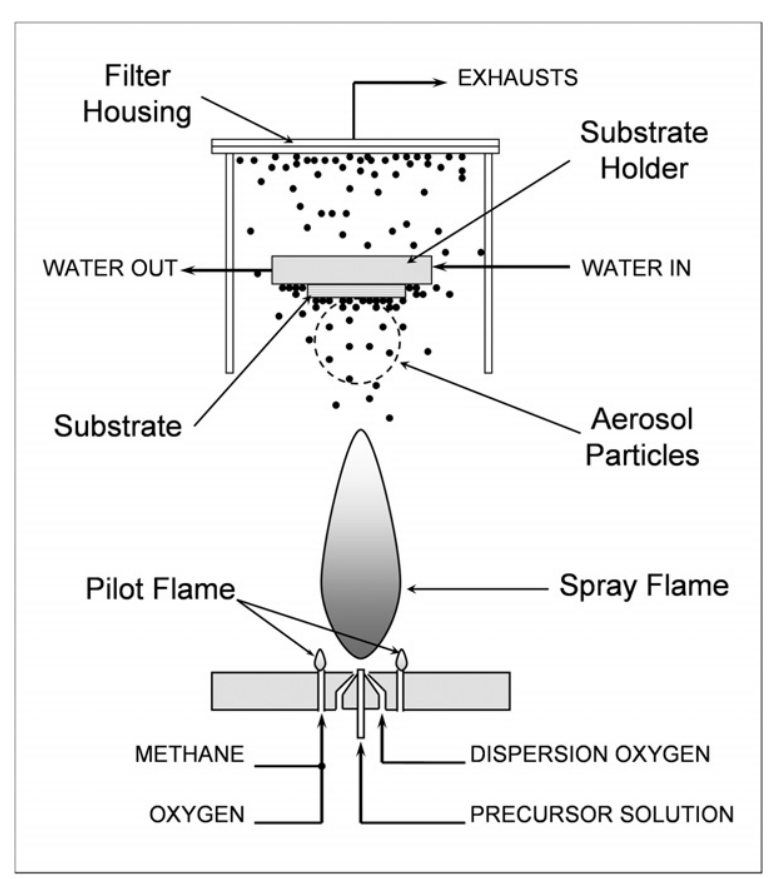

Figure 1. Schematic of the FAD setup consisting of an FSP burner and a cooled substrate holder. The FSP-made aerosol directly impinges on the substrate leading to the deposition of a porous nanoparticle film.

using the Rietveld fundamental parameter refinement (with the software TOPAS 3.0, Bruker) [39]. The elemental composition of the phosphor powder was investigated by energy dispersive $x$-ray spectroscopy (EDX) with an EDAX Pegasus system (installed into a scanning electron microscope Quanta 200 FEG, FEI). Estimation of the relative concentration of europium was performed by the EDAX ZAF quantification method (implemented in the software available from EDAX) using Y-L and Eu-L lines. The specific surface area (SSA) of powders was measured by the Brunauer-EmmettTeller (BET)-method (Micromeritics Tristar 3000). The BET equivalent diameter was calculated using the density of $5.3 \mathrm{~g} \mathrm{~cm}^{-3}$ (obtained from XRD). The morphology of phosphor particles was observed by tunneling electron microscopy (TEM: CM30 microscope, acceleration voltage $300 \mathrm{kV}$ ). The morphology of deposited layers was investigated by scanning electron microscopy (SEM: LEO 1530 Gemini). The coating density was determined by weighing the substrates before and after the deposition. The porosity of the coatings was calculated from their apparent thickness (obtained from optical microscopy of cleaved samples) and coating density.

The photoluminescence of the nanophosphor powders (collected on the filter) was examined with a Varian Cary Eclipse fluorescence spectrometer [39]. The brightness of the luminescence was expressed by the intensity of the main emission peak (at $\lambda=612 \mathrm{~nm}$ ) and normalized to that of the commercial $\mathrm{Y}_{2} \mathrm{O}_{3}$ :Eu phosphor (L 581, Osram $\mathrm{GmbH}$, $\left.d_{50}=4.8-6.2 \mu \mathrm{m}\right)$. The measurements of the PL-emission spectra were performed by exciting the phosphor with a Xe flash lamp at a wavelength of $254 \mathrm{~nm}$. Each time, a sample of $100 \pm 10 \mathrm{mg}$ of the phosphor powder was loaded into a powder cell and then pressed towards a quartz glass plate which served as a front window. The compaction of phosphor to a volumetric porosity of $0.87 \pm 0.02$ created a powder tablet which could withstand further handling. Before performing measurements, the front window of the cell was removed in order to eliminate the influence of the Fresnel reflection of light emitted by phosphor on the interface with the glass. Photoluminescent decay curves were registered and fitted by the 'Cary Eclipse' software supplied by Varian in order to extract exponential decay time constants [39]. In this study, only the first order exponential decay is considered.

Attenuance spectra of the deposited coatings were taken with a Varian Cary 500 UV-vis-NIR spectrometer. Each coating was measured twice, once with and once without a longpass optical filter (GG-455) installed between the sample and the detector. Any significant signal in the UV-range observed in the spectra taken with the filter was due solely to the photoluminescence, and this contribution was subtracted from the original attenuance spectra (i.e., those taken without the filter).

The photoluminescence of the phosphor coatings deposited on fused silica substrates was excited by a low-pressure mercury lamp (NU-8 KL, Konrad Benda) at the wavelength of $254 \mathrm{~nm}$ and measured (in the transmission mode) by a photospectrometer (Tristan 4, MUT GmbH). Screen brightness was determined by the amplitude of the main emission peak $(\lambda=612 \mathrm{~nm})$ and then normalized to the highest brightness of the phosphor coatings deposited by sedimentation of commercial $\mathrm{Y}_{2} \mathrm{O}_{3}$ :Eu phosphor powder $(\mathrm{MaTecK} \mathrm{GmbH}, 4.5 \%$ $\mathrm{Eu}, d_{\mathrm{SEM}}=4 \mu \mathrm{m}$, coating density $2.0 \mathrm{mg} \mathrm{cm}^{-2}$, [36]). The representative coatings of the commercial phosphor (MaTecK $\mathrm{GmbH}, 4.5 \% \mathrm{Eu}, d_{\mathrm{SEM}}=4 \mu \mathrm{m}$, coating density $2.7 \mathrm{mg} \mathrm{cm}^{-2}$, relative brightness 94\%) and of submicron-sized phosphor powder deposited by flame-assisted spray pyrolysis (FASP) ( $8.5 \mathrm{~mol} \% \mathrm{Eu}, d_{\mathrm{SEM}}=0.5 \mu \mathrm{m}$, coating density $0.5 \mathrm{mg} \mathrm{cm}^{-2}$, relative brightness $91 \%$ ) were used as references. Preparation of these samples is described in more detail elsewhere [36].

\section{Results and discussion}

\subsection{Characterization of nanophosphor powders}

The choice of the FAD process parameters was based on the study on the FSP-synthesis of europium-doped yttria [39]. Here, however, the precursor feed rate was increased from 8 [39] to $11.7 \mathrm{ml} \mathrm{min}^{-1}$ in order to adjust the total heat release rates and the length of the flame as the heat of combustion of the precursor solution used in the present work was lower than the heat of combustion of the previously used 2-ethylhexanoates dissolved in EHA and toluene [39] (25.1 kJ ml ${ }^{-1}$ and $33.4 \mathrm{~kJ} \mathrm{ml}^{-1}$, respectively). The concentration of rare earth metal ions was also increased from 0.4 [39] to $0.5 \mathrm{M}$ (this work) so that, for the current FSP conditions (precursor feed rate of $11.7 \mathrm{ml} \mathrm{min}^{-1}$ and $31 \mathrm{~min}^{-1}$ of dispersion $\mathrm{O}_{2}$ ), the length of the flame was equal to that used in the previous work $(24 \mathrm{~cm})$ and the size of produced phosphor particles was comparable $\left(d_{\mathrm{BET}}=23 \mathrm{~nm}\right.$ [39] versus $24 \mathrm{~nm}$, here).

Figure 2 shows a representative EDX-spectrum of the $\mathrm{Y}_{2} \mathrm{O}_{3}: \mathrm{Eu}$ nanopowder. The samples did not contain any 


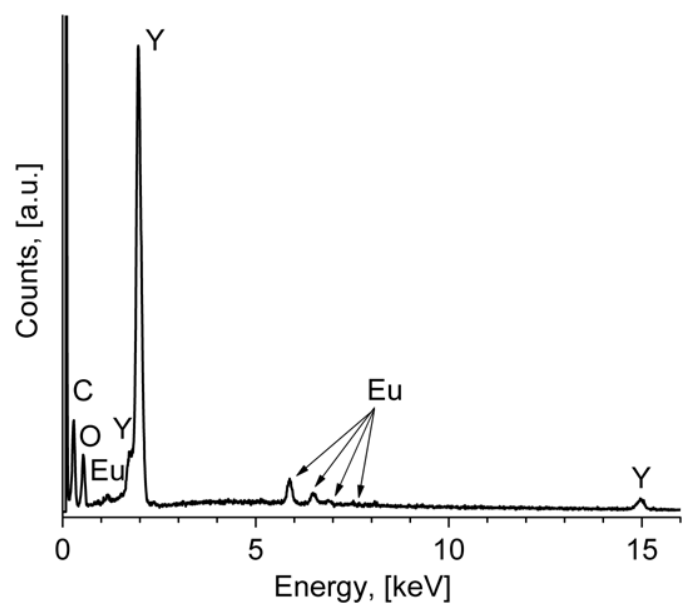

Figure 2. EDX-spectrum of $\mathrm{Y}_{2} \mathrm{O}_{3}$ :Eu nanopowder, produced from the precursor solution containing $8 \mathrm{~mol} \% \mathrm{Eu}$.

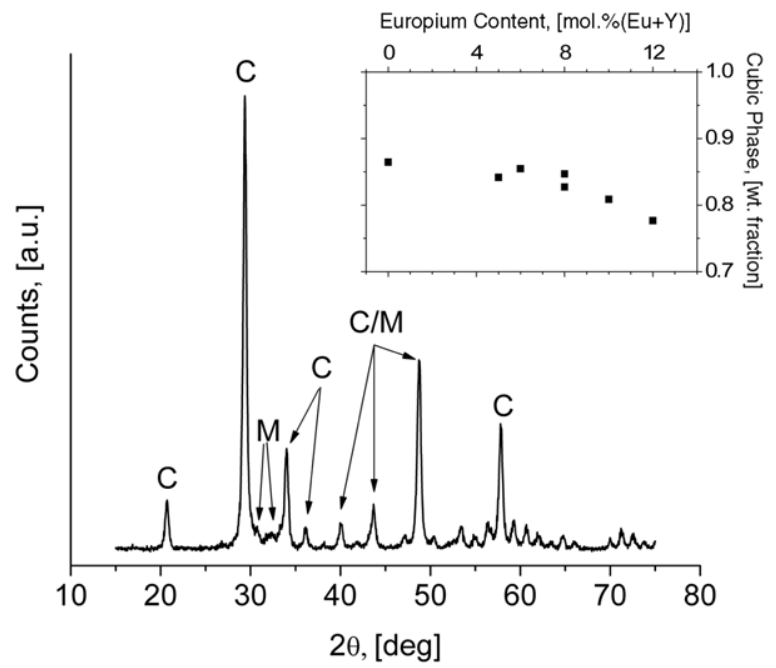

Figure 3. XRD-spectrum of undoped $\mathrm{Y}_{2} \mathrm{O}_{3}$ nanopowder. Characteristic peaks of the cubic (C) and the monoclinic (M) phases are denoted. In the inset, a relation between doping concentration and the relative amount of cubic $\mathrm{Y}_{2} \mathrm{O}_{3}$ :Eu is shown.

significant amount of elements other than yttrium, europium, and oxygen. The carbon peak comes from the material of the substrate holder for the EDX-analysis. The relative concentration of europium in the precursor solution and in the obtained powder was equal within the measurement error ( $8 \pm 1 \mathrm{~mol} \%$ and $8.8 \pm 2.6 \mathrm{~mol} \%$, respectively). The inaccuracy of europium concentration in the precursor arises from the procedure of weighing the rare earth salts before dissolving them in ethanol. Nitrates of yttrium and europium are highly hygroscopic and may contain varying amounts of absorbed water.

The XRD-spectra confirmed that as-prepared phosphor powder consisted mostly of cubic yttria with a minor admixture of the monoclinic phase (figure 3). In full agreement with literature [39], the fraction of the monoclinic phase increased with the addition of europium from less than $15 \mathrm{wt} \%$, for pure yttria, to $23 \mathrm{wt} \%$, for the powder containing $12 \mathrm{~mol} \%$ of the dopant (see the inset in figure 3 ).

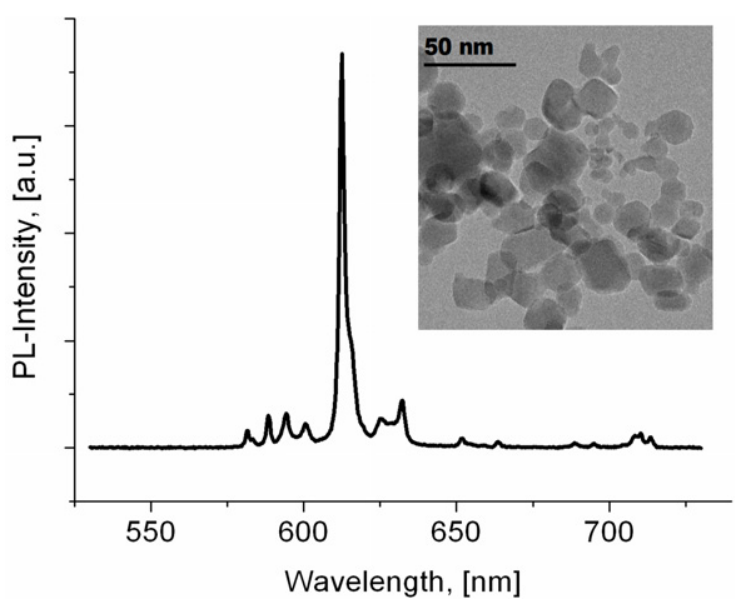

Figure 4. PL-emission spectrum of a representative sample of FSP-prepared $\mathrm{Y}_{2} \mathrm{O}_{3}:$ Eu nanophosphor $(8 \mathrm{~mol} \% \mathrm{Eu})$ with a TEM-micrograph of the powder in the inset.

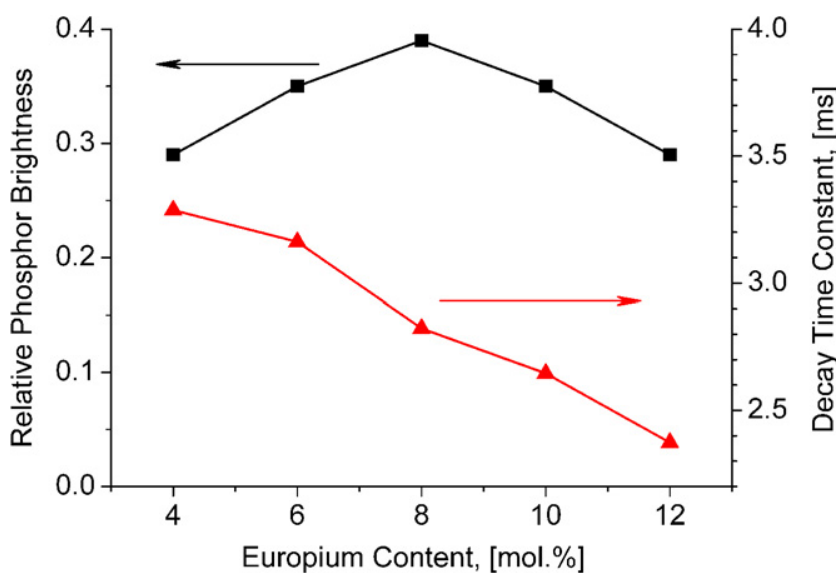

Figure 5. Phosphor brightness (squares) and the exponential decay time constant (triangles) as a function of Eu-content.

The spectra of photoluminescence (figure 4) and particle morphology (inset in figure 4) were also very similar to that of the $\mathrm{Y}_{2} \mathrm{O}_{3}$ :Eu nanophosphor synthesized from the different precursor mixture [39]. Thus, it can be concluded that the nitrates of rare earth elements dissolved in ethanol and 2ethylhexanoic acid can be used instead of the significantly more expensive 2-ethylhexanoates.

The influence of the dopant concentration on the intensity and the exponential decay time constant of photoluminescence is presented in figure 5. The brightness of nanophosphor powders reached $40 \%$ of that of the commercial reference, which is in the range of reported values for $\mathrm{Y}_{2} \mathrm{O}_{3}$ :Eu nanophosphors [41, 42]. For experiments on the deposition of nanophosphor screens, the optimal europium concentration of $8 \mathrm{~mol} \%$ was used. Although this value is in agreement with that of submicron-sized $\mathrm{Y}_{2} \mathrm{O}_{3}$ :Eu obtained by FASP [36], it is higher than the $5 \mathrm{wt} \%$ value found in the previous study on the FSP-synthesis of $\mathrm{Y}_{2} \mathrm{O}_{3}$ :Eu nanophosphor $[38,39]$. Currently, there is a large spread in the reported optimum composition of europium-doped yttria [39], while no concluding trends were found so far. 


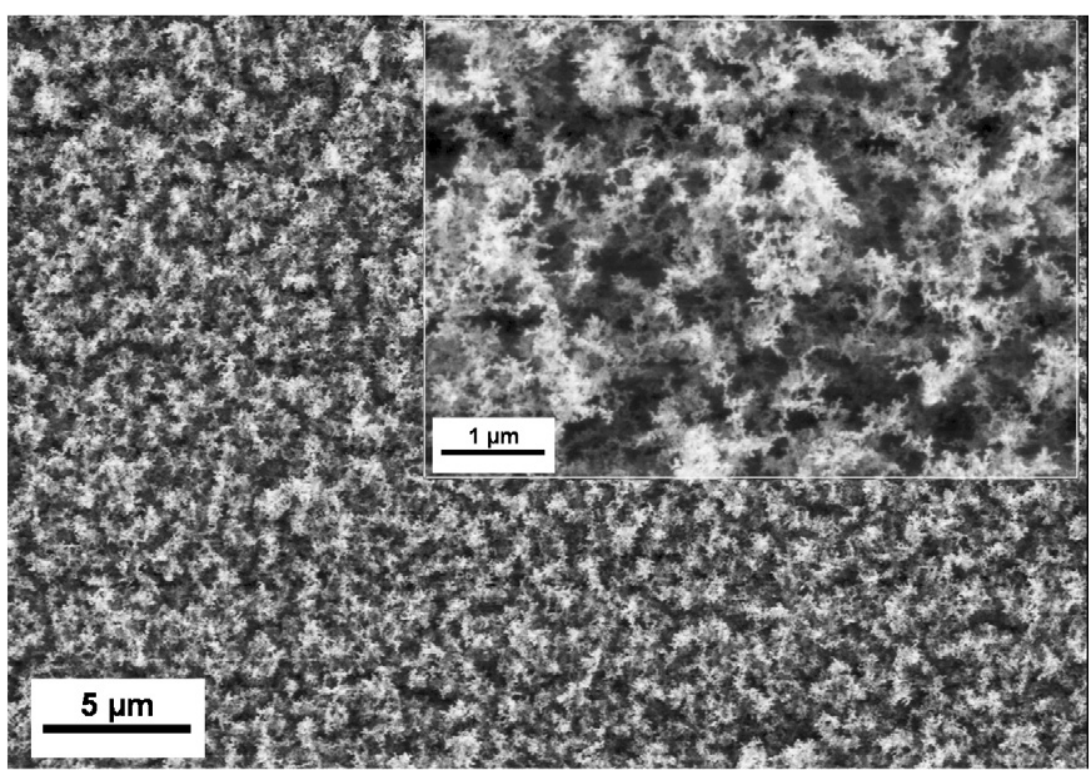

Figure 6. Morphology of FAD-deposited $\mathrm{Y}_{2} \mathrm{O}_{3}$ nanoparticle coatings.

The PL-decay time constant for nanophosphor containing $8 \mathrm{~mol} \%$ of the dopant was $2.8 \mathrm{~ms}$ (figure 5). The constant gradually decreased with higher doping concentrations (e.g., $2.4 \mathrm{~ms}$ for $12 \mathrm{~mol} \% \mathrm{Eu}$ ). Nevertheless, it was much longer than that of micron- and submicron-sized phosphors (1.0-1.4 ms) [36], which is also in agreement with the literature $[3,4,39]$.

\subsection{Characterization of the deposited nanophosphor screens}

The morphology of the obtained FAD-deposits is shown in figure 6. Aerosol particles formed a highly porous foam-like structure on the surface of the substrate, very similar to that of other FAD-deposits (e.g., of tin oxide coatings $[29,40])$ or the yttria nanoparticles deposited by gasphase condensation [43]. It is worth noting that the volumetric porosity of the phosphor coating $(0.973 \pm 0.004$, e.g., coating density $1.06 \pm 0.06 \mathrm{mg} \mathrm{cm}^{-2}$, coating thickness $74 \pm 4 \mu \mathrm{m}$ ) was close to that of uncompacted powder, as collected on the filter ( $0.977 \pm 0.006$, e.g., $100 \pm 1 \mathrm{mg}$ of phosphor powder occupied a volume of $0.83 \pm 0.18 \mathrm{~cm}^{3}$ ). The average deposition rate was $0.22 \mathrm{mg} \mathrm{cm}^{-2} \mathrm{~min}^{-1}$. Uniform deposits for a wide range of coating densities $\left(0.23-3.8 \mathrm{mg} \mathrm{cm}^{-2}\right)$ were obtained.

The change in the optical attenuance of the layers of $\mathrm{Y}_{2} \mathrm{O}_{3}$ :Eu phosphor nanoparticles for increasing coating density is presented in figure 7. For comparison, the spectra of the reference samples (deposited by FASP and by the gravitational sedimentation of the commercial phosphor powder [36]) are also shown. The attenuance of both reference phosphor coatings is approximately equal and constant over the entire wavelength range where the absorption of europium-doped yttria is negligible $(\lambda>270 \mathrm{~nm})$. It can be concluded that, in full consistency with literature, the scattering coefficient of the reference samples does not depend on the wavelength of incident light [14]. At the same time, the scattering of light transmitted through the layers of nanophosphor has an expressed dependence on wavelength (similar to Rayleigh

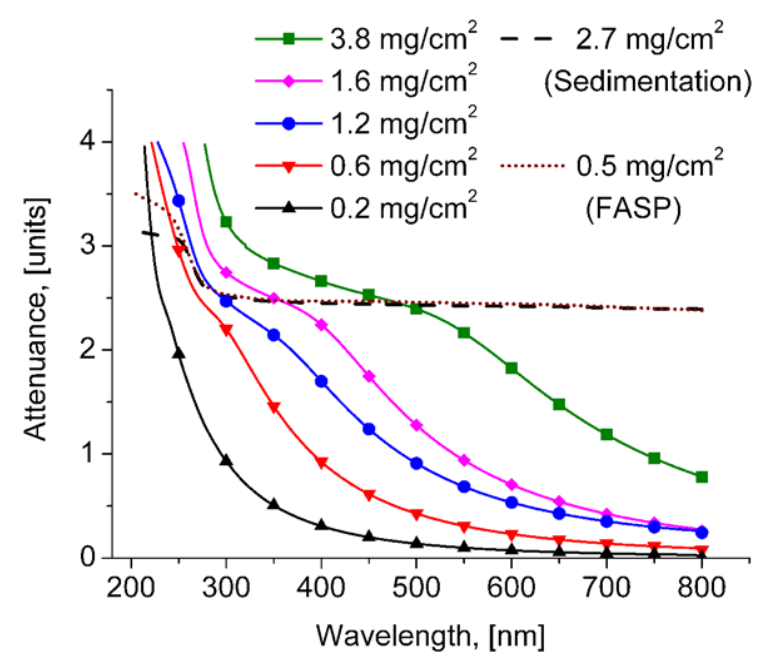

Figure 7. Attenuance spectra of the reference samples and $\mathrm{Y}_{2} \mathrm{O}_{3}: \mathrm{Eu}$ nanophosphor coatings $(8 \mathrm{~mol} \% \mathrm{Eu})$ of the different coating densities.

scattering) and substantially decreases in the visible range, which also agrees with theory and reported data [15, 44, 45]. For example, at the wavelength of the main emission peak of $\mathrm{Y}_{2} \mathrm{O}_{3}: \mathrm{Eu}(\lambda=612 \mathrm{~nm})$, the attenuance of the FAD-deposits is about 2 units of attenuance, corresponding to two orders of magnitude (or 99\%) lower than that of the reference coatings. Such a decrease in the scattering of emitted light should substantially improve the resolution of phosphor screens (i.e., preclude blurring of displayed images [14]).

In addition to the expected improvement of screen resolution, reduced scattering significantly affects the relationship between screen density and its brightness. For excitation at $254 \mathrm{~nm}$, the transmission-mode brightness of the nanophosphor screens reaches saturation at $1.2 \mathrm{mg} \mathrm{cm}^{-2}$ (figure 8).

The corresponding value of attenuance shows that, for this coating density, about $99.9 \%$ of the incident UV-light is 


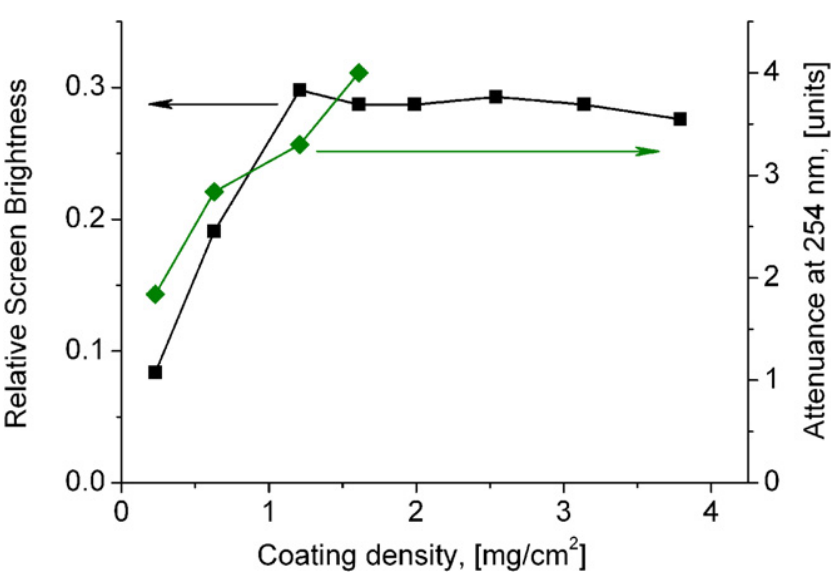

Figure 8. Screen brightness (squares) for excitation at $254 \mathrm{~nm}$ and attenuance at $254 \mathrm{~nm}$ (diamonds) as a function of the $\mathrm{Y}_{2} \mathrm{O}_{3}: \mathrm{Eu}$ nanophosphor coating density $(8 \mathrm{~mol} \% \mathrm{Eu})$.

either absorbed in the screen or scattered away. (For weakly absorbing nanoparticles, the scattering coefficient in the UVrange can be relatively large.) Thus, thicker coatings cannot have a higher PL-intensity (due to the lack of available UVphotons). At the same time, their brightness barely degrades, which is explained by the extremely weak scattering of light in the visible range.

For standard commercial phosphors, screen density always has an optimum value corresponding to the highest PL-intensity in the transmission mode. 'Thinner' screens do not absorb all available exciting radiation, whereas the light output of 'thicker' screens is degraded because some of the phosphor particles are not reached by UV-light (i.e., they do not contribute to light emission) but introduce additional scattering of emitted light. For conventional phosphors, a screen with a coating density of three times the optimum value would only achieve about $30 \%$ of the maximum transmission-mode PLintensity [46], i.e., it degrades by $70 \%$ due to the additional scattering. For FAD-deposited nanophosphor, a coating with a density of $3.8 \mathrm{mg} \mathrm{cm}^{-2}$ achieved $92 \%$ of the maximum brightness (obtained with the coating density of $1.2 \mathrm{mg} \mathrm{cm}^{-2}$ ). To the best of our knowledge, such an exceptionally weak dependence of brightness on thickness of the powder phosphor screen is observed for the first time.

It should be noted that, for excitation at $254 \mathrm{~nm}$, measured values of the relative brightness of nanophosphor coatings did not exceed $30 \%$, whereas filter-collected nanophosphor powders compacted in the powder cell of the spectrometer achieved $40 \%$ of the relative brightness. This difference may, to some extent, be explained by the fact that the commercial phosphors, which were used as references for characterization of filter-collected phosphor powders and for characterization of deposited coatings (purchased from Osram $\mathrm{GmbH}$ and from MaTecK GmbH, respectively), were different. The latter phosphor could have a somewhat higher efficiency leading to a lowered relative brightness of nanophosphor samples in comparison to another reference. However, there are two important issues that can substantially affect the measured brightness of nanophosphor coatings regardless of the reference. First, there is an optical interaction with the

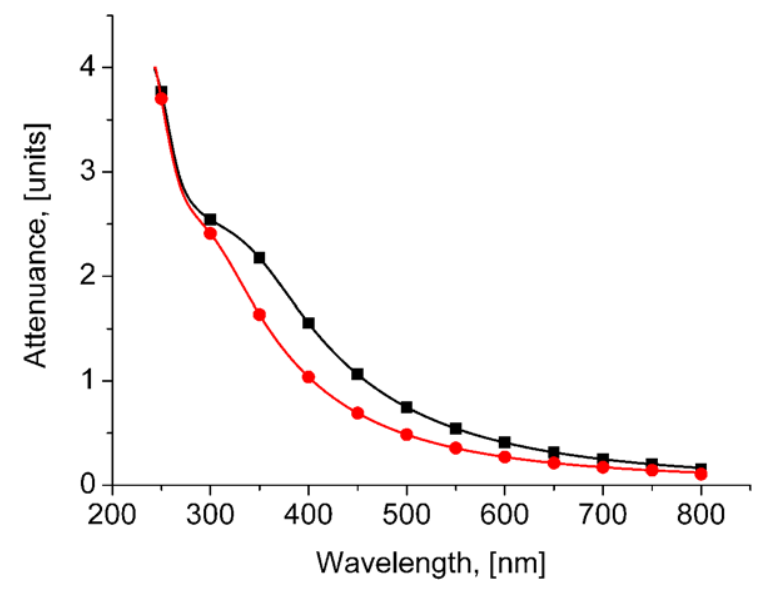

Figure 9. Attenuance spectra of an $\mathrm{Y}_{2} \mathrm{O}_{3}$ :Eu nanoparticle coating ( $1.2 \mathrm{mg} \mathrm{cm}^{-2}, 8 \mathrm{~mol} \% \mathrm{Eu}$ ) before (squares) and after compaction (circles).

substrate, e.g., the reflection of emitted light at the interface between the phosphor coating and the substrate. Second, there is an influence of the different packing density (i.e., porosity) of FAD-deposits and of compacted filter-collected phosphor powders ( 0.973 versus 0.87 , respectively). Several experiments were performed in order to clarify the effect of both matters.

First, the influence of the reflection from the substrate was confirmed. Light emitted by a thin phosphor coating undergoes the Fresnel reflection at the interface with the substrate causing unequal PL-intensity in the transmission and reflection modes (i.e., of light emitted forwards and backwards). The equality can be fixed by placing a blank substrate on top of the deposited phosphor layer. The transmission-mode brightness of the nanophosphor coatings sandwiched between two quartz plates increased by $10-15 \%$, whereas that of the micrometer-sized reference sample increased only by $3 \%$. After removing the blank substrate, the PL-intensities decreased to the previous values.

Second, the influence of the porosity of the nanophosphor coatings on their PL-performance was proved as follows. A coating sandwiched between its substrate and a blank quartz plate was compacted by pressing from both sides while the blank substrate was removed afterward. A $13 \%$ increase in the transmission-mode PL-brightness due to irreversible compaction was observed (volumetric porosity decreased from $0.973 \pm 0.004$ to $0.903 \pm 0.015$ ). Attenuance spectra of the compacted coating revealed a further decrease of light scattering in the visible range (figure 9). These changes in performance of the nanophosphor coating should be attributed to the effects of dependent scattering (i.e., when the scattering from a single particle interferes with the scattering from its neighbors), which effectively changes the scattering and absorption cross sections of nanoparticles in packed beds [47].

The above experiments show that packing density of phosphor particles (i.e., porosity of the phosphor layer) and light reflection from the supporting substrate significantly influence the PL-performance of the nanophosphor screens. A combination of both effects may well explain the lower brightness of the FAD-deposited coatings in comparison to the corresponding filter-collected phosphor powders. 


\section{Conclusions}

Optical properties of nanophosphors are promising for applications that require extremely high resolution. In this work, rapid (within minutes) manufacturing of nanophosphor screens by FAD was demonstrated for the first time. Coatings of $\mathrm{Y}_{2} \mathrm{O}_{3}$ :Eu phosphor with an average particle size $\left(d_{\mathrm{BET}}\right)$ of $24 \mathrm{~nm}$ were obtained on fused silica substrates with the average deposition rate of $0.22 \mathrm{mg} \mathrm{cm}^{-2} \mathrm{~min}^{-1}$. It was shown that the liquid precursors for FSP/FAD can be prepared directly from inorganic salts of corresponding elements, thus, substantially decreasing the costs of consumable materials.

Remarkably, the FAD-coatings demonstrated up to two orders of magnitude (or 99\%) weaker light scattering in the visible range than the coatings made of commercial micrometer-sized or submicron-sized phosphor powders. As a result, a constant PL-output (repeatable within $\pm 8 \%$ ) was maintained over a wide range of coating densities (from 1.2 to $3.8 \mathrm{mg} \mathrm{cm}^{-2}$ ). It is furthermore expected that nanophosphor screens will approach the resolution limits set by diffraction of light.

The maximum transmission-mode brightness of FADdeposited phosphor coatings, for excitation at $254 \mathrm{~nm}$, was $30 \%$ of that of the corresponding reference screen made of the commercial phosphor powder. The PL-performance was found to be substantially affected by reflection of light from the substrate and by the packing density of phosphor particles. The brightness of the nanophosphor screen could be increased by $13 \%$ upon mechanical compaction of the deposits (volumetric porosity changed from 0.97 to 0.90 ). At the same time, light scattering in the visible range has further decreased. Therefore, it can be concluded that, together with the shortening of decay times of photoluminescence [48], the brightness and light scattering properties of nanophosphor coatings can be improved by decreasing the porosity of the deposits.

\section{Acknowledgments}

The authors would like to thank Drs R Strobel and F A Yildirim for the fruitful conversations and support.

\section{References}

[1] Bhargava R N 1996 J. Lumin. 7085

[2] Tissue B M 1998 Chem. Mater. 102837

[3] Liu G and Chen X 2007 Handbook on the Physics and Chemistry of Rare-Earths vol 37, ed K A Gschneider Jr et al (Amsterdam: North-Holland/Elsevier) p 99

[4] Ronda C R and Jüstel T 2008 Luminescence: From Theory to Applications ed C R Ronda (Weinheim: Wiley-VCH) p 35

[5] Zachau M and Konrad A 2004 Solis State Phenom. 99/100 13

[6] Haranath D, Chander H, Sharma P and Singh S 2006 Appl. Phys. Lett. 89173118

[7] Jia D, Wang Y, Guo X, Li K, Zou Y K and Jia W 2007 J. Electrochem. Soc. $154 \mathrm{~J} 1$

[8] Psuja P, Hreniak D and Strek W 2007 J. Nanomater. 200781350

[9] Dosev D, Nichkova M and Kennedy I M 2008 J. Nanosci. Nanotechnol. 81052

[10] Mupparapu M, Bhargava R N, Mullick S, Singer S R, Taskar N and Yekimov A 2005 Int. Congr. Ser. 12811256
[11] Kim S-Y, Park J-K, Kang S-S, Cha B-Y, Cho S-H, Shin J-W, Son D-W and Nam S-H 2007 Nucl. Instrum. Methods Phys. Res. A $\mathbf{5 7 6} 70$

[12] Rossmann K 1969 Radiology 93257

[13] Koch A, Raven C, Spanne P and Snigirev A 1998 J. Opt. Soc. Am. A 151940

[14] Zege E P, Ivanov A P and Katsev I L 1991 Image Transfer Though a Scattering Medium (Berlin: Springer) p 318

[15] Mishchenko M I, Travis L D and Lacis A A 2002 Scattering, Absorption and Emission of Light by Small Particles (Cambridge: Cambridge University Press) p 238

[16] Mesko M, Ou Q, Matsuda T, Ishikawa T, Veis M, Antos R, Ogino A and Nagatsu M 2009 Nanotechnology 20255201

[17] Soules T F and Klatt W A 1988 J. Illum. Eng. Soc. 1792

[18] Konrad A, Almanstoetter J, Reichardt J, Gahn A, Tidecks R and Samwer K 1999 J. Appl. Phys. 851796

[19] Zhang H, Cui Y, Men Y and Liu X 2006 J. Lumin. 121601

[20] Smith A, Belomoin G, Nayfeh M H and Nayfeh T 2003 Chem. Phys. Lett. 372415

[21] Khan A F, Haranath D, Yadav R, Singh S, Chawla S and Dutta V 2008 Appl. Phys. Lett. 93073103

[22] Pang M L, Lin J, Cheng Z Y, Fu J, Xing R B and Wang S B 2003 Mater. Sci. Eng. B 100124

[23] Jang W-S and Grunlan J C 2005 Rev. Sci. Instrum. 76103904

[24] Varahramyan K and Lvov Y 2006 Proc. Inst. Mech. Eng. Part N J. Nanoeng. Nanosyst. 22029

[25] Lu Y, Liu G L and Lee L P 2005 Nano Lett. 55

[26] Fuller S B, Wilhelm E J and Jacobson J M 2002 IEEE ASME J. Microelectromech. Syst. 1154

[27] Strobel R and Pratsinis S E 2007 J. Mater. Chem. 174743

[28] Mueller R, Jossen R and Pratsinis S E 2004 J. Am. Ceram. Soc. 87197

[29] Tricoli A, Graf M, Mayer F, Kühne S, Hierlemann A and Pratsinis S E 2008 Adv. Mater. 203005

[30] Kühne S, Graf M, Tricoli A, Mayer F, Pratsinis S E and Hierlemann A 2008 J. Micromech. Microeng. 18035040

[31] Tricoli A, Righettoni M and Pratsinis S E 2009 Nanotechnology 20315502

[32] Chew S Y et al 2009 J. Power Sources 189449

[33] Tricoli A, Righettoni M and Pratsinis S E 2009 Langmuir 2512578

[34] Tammela S, Soderlund M, Koponen J, Philippov V and Stenius P 2006 Proc. SPIE $611661160 \mathrm{G}$

[35] Pimenoff J, Hovinen A and Rajala M 2006 Proc. 6th Int. Conf. on Coatings on Glass and Plastics (Dresden, Germany, June 18-22, 2006) p 135

[36] Kubrin R, Bauhofer W and Ivankov A J 2007 J. Electrochem. Soc. $154 \mathrm{~J} 253$

[37] Kubrin R and Bauhofer W 2009 J. Lumin. 1291060

[38] Camenzind A, Strobel R and Pratsinis S E 2005 Chem. Phys. Lett. 415193

[39] Camenzind A, Strobel R, Krumeich F and Pratsinis S E 2007 Adv. Powder Technol. 185

[40] Mädler L, Roessler A, Pratsinis S E, Sahm T, Gurlo A, Barsan N and Weimar U 2006 Sensors Actuators B 114283

[41] Dhanaraj J, Jagannathan R, Kutty T R N and Lu C-H 2001 J. Phys. Chem. B 10511098

[42] Ye X, Zhuang W, Hu Y, He T, Huang X, Liao C, Zhong S, Xu Z, Nie H and Deng G 2009 J. Appl. Phys. 105064302

[43] Tissue B M 2006 Phosphor Handbook 2nd edn, ed W M Yen et al (Boca Raton, FL: CRC Press) p 355

[44] Hayakawa S 2006 Phosphor Handbook 2nd edn, ed W M Yen et al (Boca Raton, FL: CRC Press) p 893

[45] Kasuya R, Kawano A, Isobe T, Kuma H and Katano J 2007 Appl. Phys. Lett. 91111916

[46] Fran Y-S and Tseng T-Y 1999 J. Phys. D: Appl. Phys. 32513

[47] Prasher R 2007 J. Appl. Phys. 102074316

[48] Meltzer R S, Feofilov S P, Tissue B M and Yuan H B 1999 Phys. Rev. B 60 R14 013 